Pediat. Res. 9: 703-705 (1975)

Bilirubin

DNA

jaundice

neonate photoactivation

photodegradation

phototherapy

\title{
The Bilirubin-induced Photodegradation of Deoxyribonucleic Acid
}

\author{
WILLIAM T. SPECK ${ }^{(17)}$ AND HERBERT S. ROSENKRANZ \\ Departments of Pediatrics and Microbiology, College of Physicians and Surgeons, Columbia University, \\ New York, New York, USA
}

\begin{abstract}
Extract
The widespread use of phototherapy for neonatal jaundice has caused some concern since little is known about the cellular consequences of such treatment. The present study was undertaken to determine the effects of photoactivated bilirubin on the structure of purified deoxyribonucleic acid. DNA illuminated in the presence of bilirubin exhibited altered physical chemical properties as evidenced by (1) a changed thermal helix coil transition profile, (2) a sensitivity of the treated DNA to alkaline degradation, and (3) a limited depolymerization of single-stranded DNA. The above changes were observed with a total light dosage representing only $5 \%$ of that received by a newborn infant during a 24 -hr period of phototherapy in our nursery.
\end{abstract}

\section{Speculation}

In view of the known relationship between ability to modify cellular DNA and mutagenic and/or carcinogenic potential, the present results suggest that phototherapy is a complex process which may have potentially dangerous sequelae.

The effect of new environmental agents on child health is a subject of considerable interest at the present time (2). Of special concern are the long term effects of such agents and more specifically their carcinogenic and mutagenic potentials which are believed to result from the ability of such agents to alter intracellular DNA $(3,4,8)$. In 1958 , a new environmental agent was introduced into the practice of pediatrics: high intensity phototherapy for the treatment of hyperbilirubinemia in the neonate. Although no immediate or serious side effects of phototherapy have been reported, very little is known about the cellular events which may result from irradiation of neonates with high intensity visible light (1). Because of these considerations we have undertaken a systematic study of the potential genetic effects of phototherapy. This report represents our preliminary findings regarding the effect of the photoactivation of bilirubin on the structure of the DNA molecule.

\section{MATERIALS AND METHODS}

Calf thymus and bacterial (Micrococcus lysodeikticus) DNAs were purchased from Miles Laboratories, Inc. and bilirubin from Sigma Chemical Co. The DNA was dissolved in $0.015 \mathrm{M} \mathrm{NaCl}$ containing $0.0015 \mathrm{M}$ sodium citrate. Single-stranded DNA was prepared by heating these samples at $100^{\circ}$ for $6 \mathrm{~min}$ and then immersing them immediately in an ice bath. The DNA solutions were then supplemented either with dimethylsulfoxide (DMSO) or bilirubin dissolved in DMSO. Portions of these solutions were kept in the dark as controls whereas their companion solutions were illuminated with a phototherapy unit utilizing either white lights (Dura-Test Vita Lite) or special high energy blue Westinghouse bulbs (F20T12-BB) which have a peak emission at $450 \mathrm{~nm}$. The phototherapy unit was protected from direct sunlight and air cooled to maintain samples at $23^{\circ}$. The sample distance from the light sources was adjusted to maintain a fluence rate (at $450 \mathrm{~nm}$ ) of
141 and $652 \mu \mathrm{w} / \mathrm{cm}^{2}$ for the white and blue lights, respectively. Photometric measurements were made with the IL600A photometer coupled to the IL600 photodensitometer manufactured by International Light, Inc. (13).

Initially for the determination of the physical chemical properties of the DNA, all excess bilirubin was removed either by passage of the DNA preparations through a Sephadex G-25 column followed by ethanol precipitation and extensive washing with ethanol or by shaking of the DNA solutions with CM-cellulose followed by centrifugation and ethanol precipitation of the supernatant fluids. In all instances, the control DNAs (free of bilirubin) were treated similarly. In subsequent experiments, excess bilirubin was not removed as it was found that such an excess in no way influenced the experimental results. Thermal helix coil transition profiles were determined as described previously (6) on DNA redissolved in $0.015 \mathrm{M} \mathrm{NaCl}$ containing $0.0015 \mathrm{M}$ sodium citrate. Sedimentation coefficients were determined in a Spinco model $\mathrm{E}$ analytical ultracentrifuge equipped with an ultraviolet optical system. Solutions of DNA $(0.003 \%)$ were spun at $50,740 \mathrm{rpm}$ and pictures taken at 2-min intervals. The photographs were traced with a Joyce-Loebl Mark III B microdensitometer and sedimentation coefficients were calculated (10). The banding properties of DNA in gradients of $\mathrm{CsCl}$ were determined as described by Mandel et al. (7). Portions of the DNA together with a reference specimen $\left(M\right.$. lysodeikticus DNA, $1.731 \mathrm{~g} / \mathrm{cm}^{3}$ or Clostridium perfringens DNA, $1.694 \mathrm{~g} / \mathrm{cm}^{3}$ ) were placed in a $\mathrm{CsCl}$ solution (density $1.70 \mathrm{~g} / \mathrm{cm}^{3}$ ) and spun at $44,770 \mathrm{rpm}$ for $24 \mathrm{hr}$. The bands formed by the specimens at their equilibrium postions were photographed and traced as above.

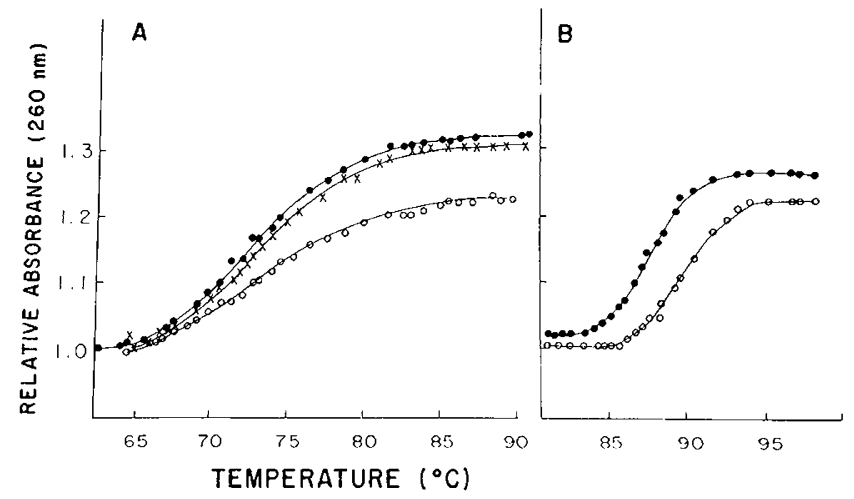

Fig. 1. Effect of illumination in the presence of bilirubin on the thermal helix coil transition profile of DNA. $A$ : Calf thymus DNA was supplemented either with bilirubin (in dimethylsulfoxide, $0.7 \mathrm{mg}$ DNA/0.33 $\mathrm{mg}$ bilirubin) or dimethylsulfoxide. Portions of each solution were kept in the dark while their companion solutions were exposed to blue lights for 4 $\mathrm{hr}\left(9.4 \times 10^{4} \mathrm{~J} / \mathrm{m}^{2}\right)$, whereupon excess bilirubin was removed, the DNA precipitated with ethanol, washed, and redissolved in $0.015 \mathrm{M} \mathrm{NaCl}$ containing $0.0015 \mathrm{M}$ sodium citrate. $\bullet$ : DNA kept in dark (identical with DNA exposed to light); $\times$ : DNA-bilirubin mixture kept in dark; $O$, DNA-bilirubin mixture illuminated. $B: M$. lysodeikticus DNA was processed as described above except that samples were illuminated for $6 \mathrm{hr}$ with white light $\left(30,456 \mathrm{~J} / \mathrm{m}^{2}\right)$. O DNA-bilirubin mixture kept in dark (similar to DNA controls), O: DNA-bilirubin mixture exposed to light. 
Table 1. Effect of illumination in presence of bilirubin on the physical chemical properties of DNA ${ }^{1}$

\begin{tabular}{|c|c|c|c|c|c|c|c|}
\hline & \multirow[b]{2}{*}{ Additions } & \multirow{2}{*}{$\begin{array}{l}\text { Illumination } \\
\qquad\left(\mathrm{J} / \mathrm{m}^{2}\right)\end{array}$} & \multicolumn{3}{|c|}{ Sedimentation coefficients, $S$} & \multicolumn{2}{|c|}{ Buoyant density $\left(\mathrm{g} / \mathrm{cm}^{3}\right)$} \\
\hline & & & Untreated & Heated & Alkali & Untreated & Heated \\
\hline \multirow[t]{7}{*}{ I: } & Micrococcus DNA (DS) & & & & & & \\
\hline & None & 0 & 18.7 & 18.1 & 18.8 & 1.732 & 1.744 \\
\hline & None & Blue $(140,832)$ & 17.5 & 17.1 & 19.4 & 1.733 & 1.744 \\
\hline & Bilirubin & 0 & 17.7 & 16.8 & 17.5 & 1.733 & 1.744 \\
\hline & Bilirubin & Blue $(140,832)$ & 16.6 & 16.9 & 18.1 & 1.733 & 1.742 \\
\hline & None & White $(30,456)$ & 17.7 & 18.4 & & 1.732 & 1.742 \\
\hline & Bilirubin & White $(30,456)$ & 18.6 & 18.3 & & 1.732 & 1.741 \\
\hline \multirow[t]{5}{*}{ II: } & Calf thymus DNA (DS) & & & & & & \\
\hline & None & 0 & 22.4 & & 20.1 & 1.704 & 1.719 \\
\hline & None & Blue $(70,416)$ & 25.1 & & 21.3 & 1.704 & 1.720 \\
\hline & Bilirubin & 0 & 24.2 & & 22.6 & 1.705 & 1.720 \\
\hline & Bilirubin & Blue $(70,416)$ & 20.0 & & 17.9 & 1.703 & 1.720 \\
\hline \multirow[t]{5}{*}{ III: } & Calf thymus DNA (SS) & & & & & & \\
\hline & None & 0 & 19.5 & 18.1 & 11.8 & 1.719 & \\
\hline & None & Blue $(70,416)$ & 17.2 & 15.9 & 13.3 & 1.719 & \\
\hline & Bilirubin & 0 & 17.8 & 12.2 & 10.1 & 1.719 & \\
\hline & Bilirubin & Blue $(70,416)$ & 12.3 & 11.0 & 8.5 & 1.720 & \\
\hline \multirow[t]{3}{*}{ IV: } & Calf thymus DNA (DS) & & & & & & \\
\hline & None & 0 & 18.7 & 21.3 & & 1.704 & \\
\hline & $N$-Hydroxyurethan, $0.05 \mathrm{M}, 6 \mathrm{hr}$ & 0 & 17.7 & 10.3 & & 1.705 & \\
\hline
\end{tabular}

'DS: double-stranded (native) DNA; SS: single-stranded (heat-denatured) DNA. Solutions of DNA ( $1 \mathrm{mg}$ per ml of $0.015 \mathrm{M} \mathrm{NaCl}$ containing 0.0015 M sodium citrate) were supplemented with bilirubin in dimethylsulfoxide (DMSO) such that the final concentrations of DNA and bilirubin were 0.7 and $0.3 \mathrm{mg} / \mathrm{ml}$, respectively. DNA specimens not receiving bilirubin were supplemented with DMSO only. Samples were either kept in the dark or exposed to phototherapy lights. Upon completion of the illumination, samples were processed for determination of physicochemical properties.

\section{RESULTS}

Illumination of DNA in the presence of bilirubin resulted in alterations of the shape of the thermal helix coil transition profile of the DNA and a decrease in hyperchromic shifts (Fig. 1). These changes were seen with DNA of different base compositions; i.e., calf thymus and $M$. lysodeikticus DNAs have guanine + cytosine contents of $40 \%$ and $72 \%$, respectively. Similar changes were not observed when the DNA was irradiated in the absence of bilirubin, or when DNA mixed with similar concentrations of bilirubin was kept in the dark.

Despite the changes in the thermal helix coil transition profile of DNA illuminated in the presence of bilirubin, there were no consistent alterations in other physical chemical properties; e.g., buoyant density and sedimentation coefficients. However, on several occasions the sedimentation coefficients of the DNA illuminated in the presence of bilirubin were slightly decreased. Thermal denaturation of the DNA followed by sedimentation analysis did not reveal "hidden breaks" which might have been stabilized by the double-stranded structure. Such hidden breaks would have been evidenced by a significant drop in sedimentation coefficient after heating, because after heat denaturation the separated strands are much smaller. Such an effect was seen with the DNA sample exposed to $N$-hydroxyurethan (Table 1), an agent known to cause cleavage of phosphodiester linkages (9).

Denaturation of DNA under alkaline conditions resulted in a proportionally greater decrease in the sedimentation coefficient of DNA illuminated in the presence of bilirubin when compared with control DNA with and without bilirubin but kept in the dark. This finding, which was also observed consistently with DNA of varying base compositions, suggests that upon illumination in the presence of bilirubin the DNA is modified in a subtle manner which is generally not detectable by hydrodynamic measurements; however, such modification does result in an abnormal sensitivity of the DNA to alkali with a cleavage of the DNA backbone and a corresponding decrease in sedimentation coefficient.

Illumination of single-stranded DNA in the presence of bilirubin resulted in significant decreases in sedimentation coefficients, even in the absence of alkaline treatment. Subsequent exposure of such single-stranded DNA to $\mathrm{NaOH}$ increased this effect even further (Table 1). (It can be calculated (5) that the decrease in sedimentation coefficient from 19.5 to $12.3 \mathrm{~S}$ which was observed upon illumination in the presence of bilirubin (Table 1) corresponds to a 4.1-fold drop in molecular weights.)

\section{DISCUSSION}

The present findings demonstrate that the photoactivation of bilirubin has an effect on the structure of the DNA molecule in vitro. These structural changes are magnified when singlestranded, rather than double-stranded DNA, is exposed to the bilirubin before illumination. The more dramatic effects observed with the single-stranded molecule may be a result of structural factors such as the inability of the rather large bilirubin molecule to approach and/or react with specific bases in the double helix. Such steric factors are not present when "disorganized" or singlestranded DNA is exposed to the bilirubin molecule. A similar reaction might conceivably occur in vivo since at any one time a significant proportion of the DNA of living cells is in the singlestranded configuration.

The exact chemical nature of the reaction between photoactivated bilirubin and the DNA molecule remains to be elucidated. We have demonstrated that $(I)$ this reaction occurs with illumination by visible light at $450 \mathrm{~nm}$ (considered by many the most effective wavelength for the treatment of neonatal jaundice), (2) the dosage of $(450 \mathrm{~nm})$ light utilized to produce these structural changes is minimal, e.g., approximately $7 \times 10^{4} \mathrm{~J} / \mathrm{m}^{2}$ when compared with the dose received by a neonate in our nursery for a 24-hr period, i.e., ca. $1.31 \times 10^{6} \mathrm{~J} / \mathrm{m}^{2}$, (3) the observed changes occur in the presence of bilirubin concentrations that are not uncommon in the severely jaundiced neonate.

Earlier work in our laboratory demonstrated that visible light $(450 \mathrm{~nm})$ was capable of inducing mutations in prokaryotic and eukaryotic (yeast) cells and that illumination of DNA (in vitro as well as in vivo) in the presence of physiologic concentrations of riboflavin resulted in alterations in the macromolecular structure of this biopolymer $(11,12)$. These earlier findings, together with 
the present ones which suggest the existence of a photochemical reaction between DNA and bilirubin are somewhat disquieting, particularly when one considers that mutagens and chemical carcinogens derive their biologic activity from the ability to react with DNA. Our results suggest that phototherapy of neonates is a complex process which may generate a number of potentially dangerous genetic side effects.

\section{SUMMARY}

The widespread use of phototherapy in the treatment of neonatal jaundice is causing concern because little information is available on its effects on subcellular structure and function. The present study deals with the effects on the macromolecular structure of DNA illuminated in the presence of bilirubin. The results indicate a bilirubin-induced photodegradation of this biopolymer.

\section{REFERENCES AND NOTES}

1. Behrman, R. E., Brown, A. K., Currie, M. R., Hastings, J. W., Odell, G. B., Schaffer, R., Setlow, R. B., Vogl, T. P., Wurtman, F. J., Anderson, R. J., Kostkowski, H. J., and Simopoulos, A. P.: Preliminary report of the committee on phototherapy in the newborn infant. J. Pediat. 84: 135 (1974).

2. Committee on Environmental Hazards: The susceptibility of the fetus and child to chemical pollutants. Pediatrics, 53 (suppl. II) (I974).

3. Department of Health, Education and Welfare Publication No. (National Institutes of Health) 74-570, National Cancer Program, Digest of Scientific Recommendations for the National Cancer Program. (United States Department of Health, Education and Welfare, National Institutes of Health, 1974).

4. Department of Health, Education and Welfare Publication No. (National Institutes of Health) 74-569, National Cancer Program, The Strategic Plan,
January 1973 edition. (United States Department of Health, Education and Welfare, National Institutes of Health, 1974).

5. Eigner, J.: Moleculat weight and conformation of DNA. Methods Enzymol., 12B: 386 (1968).

6. Mandel, M., and Marmur, J.: Use of ultraviolet absorbance-temperature profile for determining the guanine plus cytosine content of DNA. Methods Enzymol., I2B: 195 (1968).

7. Mandel, M., Schildkraut, C. L., and Marmur, J.: Use of $\mathrm{CsCl}$ density gradient analysis for determining the guanine plus cytosine content of DNA. Methods Enzymol., 12B: 184 (1968).

8. Mrak, E. M.: Report of the Secretary's Commission on Pesticides and their relationship to environmental health. United States Department of Health, Education and Welfare, December 1969 (0-371-074). (United States Government Printing Office Washington, D.C.).

9. Mullinix, K. P., Rosenkranz, S., Carr, H. S., and Rosenkranz, H. S.: Reaction between DNA and N-hydroxyurethan. Biochim. Biophys. Acta, 312: 1 (1973).

10. Rosenkranz, H. S.: Ph.D. dissertation. Cornell University Graduate School of Medical Sciences, 1959.

11. Speck, W. T., Cheng, C. C and Rosenkranz, H. S : In Vitro studies of the effects of light and riboflavin on DNA and HeLa cells. Pediat. Res., 9: 150 (1975).

12. Speck, W. T., and Rosenkranz, H. S.: Base substitution mutations induced in Salmonella strains by visibie light $(450 \mathrm{~nm})$. Photochem. Photobiol., 2l. 369 (1975).

13. Newburyport, Mass.

14. This research was supported by a gift from the George D. Smith Fund, Inc. and by the Division of Cancer Cause and Prevention, National Cancer Institute (Contract No. NO1 CP-33395).

15. Dr. W. T. Speck is the Vivian-Allen Fellow in Clinical Medicine.

16. Dr. H. S. Rosenkranz is a Research Career Development Awardee of the National Institute of General Medical Sciences, United States Public Health Service (5 K3-GM 29, 024).

17. Requests for reprints should be addressed to: W. T. Speck, M.D., Department of Pediatrics, College of Physicians and Surgeons, Columbia University, $630 \mathrm{~W}$. 168th St., New York, N. Y. 10032 (USA).

18. Accepted for publication April 23, 1975.
Pediat. Res. 9: 705-709 (1975)
Corticosteroids

CI-esterase inactivator

glomerular basement membrane

Hageman factor

kallikrein factor $\alpha$-2-macroglobulin

minimal lesion nephrotic syndrome permeability

plasma kallikrein

prekallikrein (Fletcher factor)

\title{
A Study of the Plasma Kinin-generating System in Children with the Minimal Lesion, Idiopathic Nephrotic Syndrome
}

\author{
RONALD J. KALLEN(41) AND SOO-KWANG LEE \\ Department of Pediatrics, University of Chicago-Pritzker School of Medicine and La Rabida Children's Hospital and \\ Research Center, Chicago, Illinois, USA
}

\section{Extract}

Although the precise etiologic incitant of the minimal lesion idiopathic nephrotic syndrome of childhood is not known, it is likely that a host mechanism mediates the permeability alterations of the glomerular capillary wall resulting in massive proteinuria. As a first step in examining the possibility that local kinin release may account for the proteinuria in this disorder, two parameters of the plasma kinin-generating system, plasma prekallikrein and kallikrein inhibitor, were assayed during 27 nephrotic episodes in 21 corticosteroid-responsive children. Plasma kallikrein was assayed by means of its esterase activity on a synthetic arginine ester substrate, $N$ - $\alpha$-tosyl-L-arginine methyl ester (TAMe), after activation of Hageman factor by kaolin. This activity, after subtraction of spontaneous arginine esterase activity (i.e., TAMe esterase activity measured in plasma not exposed to kaolin) is derived from prekallikrein. Plasma prekallikrein activity in 11 normal children was $99.6 \pm 2.9 \mu \mathrm{mol}$ TAMe hydrolyzed $/ \mathrm{ml}$ plasma $/ \mathrm{hr}$ (mean \pm SEM). Kallikrein inhibitor was quantified in arbitrary units. Kalli- krein inhibitor activity in 11 normal children was $0.94 \pm 0.04$ units. During the overt nephrotic syndrome, before initiation of intensive daily corticosteroid treatment, mean values were: prekallikrein, $58.5 \pm 7.24 \mu \mathrm{mol} / \mathrm{ml} / \mathrm{hr}$; and kallikrein inhibitor, $0.35 \pm 0.06$ units. After corticosteroid-induced remission occurred, mean values were: plasma prekallikrein, $118.6 \pm 3.2 \mu \mathrm{mol} / \mathrm{ml} / \mathrm{hr}$; and kallikrein inhibitor, $0.78 \pm 0.03 \mu \mathrm{mol} / \mathrm{ml} / \mathrm{hr}$. Both parameters were again assayed in 14 of the 21 children after complete cessation of corticosteroid treatment. Plasma prekallikrein was normal, 99.6 \pm $4.8 \mu \mathrm{mol} / \mathrm{ml} / \mathrm{hr}$; but kallikrein inhibitor was still somewhat depressed, $0.84 \pm 0.03$ units. A subset of 9 patients had marked depression of plasma prekallikrein to levels less than $20 \mu \mathrm{mol} / \mathrm{ml} / \mathrm{hr}$ and essentially undetectable inhibitor activity. Serum $\alpha-2$ macroglobulin was elevated in nephrotic patients: mean value during relapse, $862 \pm 29 \mathrm{mg} / 100 \mathrm{ml}$; during corticosteroid-maintaining remission, $615 \pm 29 \mathrm{mg} / 100 \mathrm{ml}$. After cessation of corticosteroids, mean serum level was $481 \pm 20 \mathrm{mg} / 100 \mathrm{ml}$. The proportional reduction of plasma prekallikrein and kallikrein inhibitor suggested that an enzyme-inhibitor complex formed in vivo, perhaps at a local 